\title{
Interpreter use in an inner city accident and emergency department
}

\author{
P Leman
}

\begin{abstract}
Objective-To determine the extent of communication problems that arose from patients whose primary language was non-English presenting to an inner city accident and emergency (A\&E) department.
\end{abstract}

Methods-A prospective survey over seven consecutive days during September 1995. All adult patients other than those directly referred by their general practitioner to an inpatient team had a questionnaire completed by the $A \& E$ doctor first seeing the patient. The doctor recorded language ability and form of interpreter used, and estimated any prolongation of the consultation and ability to improve communication by the use of additional services.

Results-103 patients (17\%) did not speak English as their primary language; 55 patients $(9.1 \%$ of the study population) had an English language ability rated as other than good, and $16(29 \%)$ of these consultations could have been improved by the use of additional interpreter services; 28 patients overall $(4.6 \%$ of the study population) required the use of an interpreter, who was usually a relative.

Conclusions-A significant number of patients presenting to $A \& E$ have difficulty in communicating in English. These consultations could often have been improved by the use of additional interpreter services. Telephone interpreter services may provide the answer for use in A\&E departments because of their instant and 24 hour availability.

(f Accid Emerg Med 1997;14:98-100)

Keywords: accident and emergency department; interpreter; communication; language problems.

Accident and

Emergency

Department, St

Thomas' Hospital,

Lambeth Palace Road,

London SE1 7EH,

United Kingdom

P Leman

Correspondence to: Dr Peter Leman MRCP, Registrar, Accident and Emergency Department, Lewisham Hospital, High Street, Lewisham, London SE13 6LH.

Accepted for publication 13 November 1996
Rapid communication with patients is an essential part of emergency medicine practice. There are, however, increasing numbers of patients, both tourists and immigrants, presenting to accident and emergency (A\&E) departments in the United Kingdom who do not speak English as their primary or secondary language. The quality of communication between hospital staff and these patients is often poor and can present major difficulties, especially outside normal hours.

There are several methods in use to improve communication with non-English speaking patients, including the use of phrase books, members of ancillary staff, relatives, bilingual health workers, and trained interpreters, both in person and over the telephone. It may be useful to find out exactly how large a problem we face and how well we cope with it.

\section{Methods}

During a one week period (08:00 h Monday to 08:00 $\mathrm{h}$ the following Monday) in September 1995 all patients who presented to the $A \& E$ department of St Thomas' Hospital in London were assessed for inclusion into the study. All children under the age of 16 years, patients directly referred to the inpatient team, and those triaged directly to the eye or gynaecology departments were excluded. All other patients had a study form attached to their notes. The first doctor seeing the patient was responsible for completion of the form. If the patient was a British citizen whose primary language was English, no further questions were required. If the patient was not a British citizen or was a British citizen whose primary language was not English then the full study form was completed. The form required the doctor to record any secondary languages spoken, status in the United Kingdom, an assessment of the patient's communication ability in English, whether an interpreter was used (and the type), any prolongation of the consultation due to language problems, and a qualitative assessment of whether or not the doctor felt that communication could have been improved by the addition of further interpreter services.

\section{Results}

A total of 1327 patients presented to A\&E during the study period. Of these, 210 were under the age of 16 , and 140 had been referred or triaged direct to inpatient teams. This left a total trial population of 977 patients, for whom 606 completed study forms were received $(62 \%)$.

Of these 606 patients, 462 were British citizens whose primary language was English; 100 of the other 144 patients were either permanent or temporary residents. The remainder were made up of tourists (30), students (7), seamen (4), refugees (2), and a businesswoman.

Of these 144 patients, 41 were non-British citizens who spoke English as their primary language and who were predominantly Americans, Jamaicans, and Nigerians. One hundred and three patients were neither British citizens nor spoke English as their primary language. Of these, 48 had a communication ability in English rated as good by the doctor seeing them. This left 55 patients who were studied in greater detail. They comprised 9.1\% (95\% 


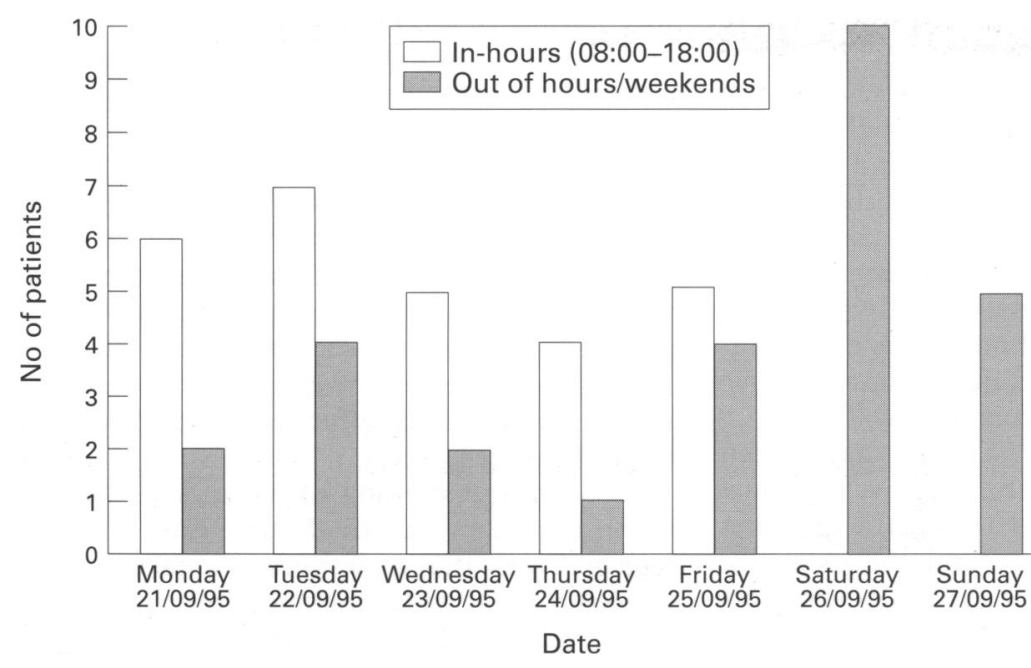

Time of presentation to $A \mathcal{E} E$ of patients whose primary language was non-English and whose English ability was other than good.

confidence interval $6.8 \%$ to $11.4 \%$ ) of the total study population.

There were 32 different primary languages spoken among these 103 patients. These were French (18), Portuguese (15), Spanish (12), Italian (6), Nigerian dialect (5), Dutch (4), German (4), Philipino (4), Bengali (3), Cypriot (3), Gujarati (3), Turkish (3), Polish (2), Chinese group (2), and one each of Africaans, Amharic, Arabic, Egyptian, Ethiopian, Finnish, Greek, Hebrew, Hindi, Hungarian, Iranian, Japanese, Maltese, Moroccan, Somalian, Swedish, Tigrinyan, Ugandan and Yugoslav (Serbo-Croat).

Of the 55 patients whose primary language was not English and whose English ability was other than good, 27 presented during office hours (Monday to Friday 08:00-18:00), and 28 presented outside these times (figure). In the 28 patients for whom some form of interpreter was actually used, the doctor seeing the patient reported that the consultation could have been improved by the use of additional interpreter services in 11 cases $(43 \%)$. In addition there were five cases where no interpreter was used because of nonavailability, and where the doctor felt interpreter services were required. The results are summarised in table 1 .

Of these 16 cases where additional interpreter services were felt necessary, six occurred

Table 1 Communication ability in English if primary language non-English

\begin{tabular}{|c|c|c|c|c|c|c|}
\hline & Nil & Few words only & $\begin{array}{l}\text { Some basic } \\
\text { understanding }\end{array}$ & Adequate & Good & Total \\
\hline No. of patients & 7 & 13 & 10 & 25 & 48 & 103 \\
\hline $\begin{array}{l}\text { No. using } \\
\text { interpreter }\end{array}$ & 7 & 12 & 4 & 5 & 0 & 28 \\
\hline
\end{tabular}

Table 2 Interpreter type

\begin{tabular}{lll}
\hline Type of interpreter used & $\begin{array}{l}\text { Number of patients } \\
(n=28)\end{array}$ & $\begin{array}{l}\text { Number in which doctor felt additional interpreter } \\
\text { services required }\end{array}$ \\
\hline Friend & 6 & $1(17 \%)$ \\
Employer/lecturer & 2 & $2(100 \%)$ \\
$\begin{array}{l}\text { Relative } \\
\text { Telephone interpreter } \\
\quad 13\end{array}$ & 1 & $2(15 \%)$ \\
Bilingice & 1 & $1(100 \%)$ \\
\hline
\end{tabular}

during office hours and 10 outside these times. By extrapolation, this would mean an annual additional interpreter usage in office hours for 313 patients and out of hours for 521 patients.

Where an interpreter was used the doctor did not specify the communication ability of the interpreter. However, the adequacy of the interpreter can be ascertained by showing which of the consultations that included an interpreter were judged to require additional interpreter services. Table 2 shows that, while employers and bilingual health workers performed poorly, relatives and friends performed well.

In all consultations with non-English speaking patients with English ability other than good (55), the consultation was felt to be prolonged in 37 cases by language difficulties, by a mean of 9.92 minutes $(95 \%$ confidence interval 5.38 to 14.46 minutes).

\section{Discussion}

The provision of health care to non-fluent English speaking patients is a major problem in many A\&E departments throughout the United Kingdom. Attention has been drawn to this by the Audit Commission, and A\&E departments are seeing an increasing number of patients for whom English is not their primary language. ${ }^{1}$ There is rarely an opportunity to prearrange formal interpreter sessions due to the nature of $A \& E$ attendances, and $A \& E$ departments must be able to offer heath care 24 hours a day and seven days a week to anybody, despite inability to communicate in English.

At St Thomas' Hospital a mixture of strategies is adopted in order to deal with language problems, and yet in over half of the consultations where some form of interpreter was used the doctor felt that this could have been improved. The difficulties of using relatives have been highlighted..$^{2-4}$ These include the relative trying to protect the patient from bad news, or colour the consultation in the light of their own prejudices. The patient may be embarrassed and not wish to reveal some part of their past history or symptoms. In rarer cases history of abuse or violence may not be forthcoming if the abuser is also acting as the interpreter. It may also be the case that the relatives' English language skills are not adequate to interpret clearly, especially medical terminology. However, this proved to be the most common source of language interpretation used in the department. It was also shown that using a relative as an interpreter was usually acceptable to the doctor assessing the communication. Only in $15 \%$ of cases where a relative was used as an interpreter did the doctor feel that additional interpreter services were required.

The number of bilingual health workers may increase as the number of EU and overseas trained doctors increases, and EU languages certainly were the commonest other primary language spoken in this study. Among the staff in our department the German and Italian bilingual health care workers were fluent in their second language. Staff members who 
spoke French rarely rated themselves above adequate in fluency. However, it is rather unlikely that the 33 languages identified in a single week could be covered internally by any $A \& E$ department in this country, and certainly not 24 hours a day. Using a list of other hospital staff to interpret can offer help with languages of the local community but has problems with confidentiality and quality of interpretation. ${ }^{2-4}$ Phrase books and other language question books and questionnaires have a small and only limited role to play. ${ }^{2-5}$

Telephone interpreter services have been gradually introduced in the UK over the last few years. ${ }^{4-6}$ They claim to answer the question of the 24 hour availability and the extensive number of languages that $A \& E$ departments would require. If we add the 11 patients where an interpreter was used but was found not to be adequate and the five cases where no interpreter was used at all and additional interpreter services were required, we have a weekly additional interpreter requirement for 16 patients. The predicted annual costs in our patient group would be $£ 23483$. (Based on 834 patients per annum; average call duration 10 minutes at $£ 2.45$ per minute $=£ 20433+$ annual fee $£ 3050) .^{7}$ This is a conservative figure, as many consultations would require more than 10 minutes of interpreter time. Additionally, if all patients whose communicating ability in English was other than good had telephone interpreter assistance, the annual figure would be even higher. From our data this would equate to 55 patients per week or 2868 patients per annum, and the annual cost would then rise to $£ 73$ 316. However, despite the problems of using relatives as interpreters this cost would seem hard to justify and use should be made of all available resources before further expenditure is accepted.

These figures are derived from one commercial source of telephone interpreter services which is currently increasing in its coverage of hospitals both in London and across the United Kingdom. This survey excluded paediatric patients with non-English-speaking parents and direct referrals to inpatient teams, which will also have a number of consultations requiring telephone interpreting services. The London Borough of Lambeth, Southwark and Lewisham provides an interpreter service but was used very infrequently in our study. The study design was unable to ascertain exactly why this might have been, but possible reasons include poor awareness of the service, unfamiliarity with the use of telephone interpreter services, or the often lengthy delays or unavailability of the appropriate bilingual interpreter that have occurred, especially in the emergency situation (personal observation). In fact the one time where the telephone interpreter service was used, the doctor marked down that additional interpreter services would be helpful. This may represent unfamiliarity with the service and the most effective means of using a telephone interpreter.

Random questioning of other A\&E department registrars in the South East Thames region reveals that a plethora of local strategies is used to deal with language problems. Some departments are using telephone interpreting on a regular basis and others using ad hoc internal staff members and relatives alone, with no access at all to additional interpreting services.

It has been shown that language difficulties are a major problem in $\mathrm{A} \& \mathrm{E}$ work and that there is much room for improvement in our communication with patients. All staff should be aware of the inherent pitfalls in using relatives to translate and should have access to 24 hour a day, seven day a week professional interpreter services. All departments should have a policy on language problems that is suited to their particular local problems but that can also cope with the unexpected patient from a language group not commonly seen in the area. It would seem that national telephone interpreter services may be able to solve a great number of these problems. However, further study would be needed to investigate their effectiveness, in terms of availability, accuracy, and actual cost.

I thank Dr D J Williams for his advice and review of the manuscript

1 Audit Commission. What seems to be the matter: communication between hospitals and patients. London: HMSO, 1994.

2 Phelan M, Parkman S. How to do tt: work with an interpreter. BMJ 1995;311:555-7.

3 Jacobs B, Kroll L, Green J, David TJ. The hazards of using a child as an interpreter. J R Soc Med 1995;88:474-5.

4 Richmond C. Phone link translates into health benefits. Hosp Doctor 16 April 1992.

5 Nasr I, Cordero M, Houmes B, Fagan J, Rydman R, Green Nasr I, Cordero M, Houmes B, Fagan J, Rydman R, Green
C. Use of a bilingual medical history questionnaire in the emergency department. Ann Emerg Med 1993;22:824-8. Pointon T Telephone interpreting service is available. BMJ

6 Pointon T. Telephone interpreting service is available. BMJ
1996;312:53.
7 Language Line. Language Line customers' guide to charges 1996 (letter received 20 March 1996) 